\title{
GEOCULTURA: PROPOSTA DE ESTUDO DA RELAÇÃO ENTRE GEODIVERSIDADE E CULTURA
}

\author{
Marcelo Martins de Moura-Fé ${ }^{(a)}$, João Victor Mariano da Silva ${ }^{(b)}$, Josielly Gonçalves Brasil ${ }^{(c)}$ \\ (a) Geógrafo. Doutor em Geografia (UFC). Professor do Departamento de Geociências, Pesquisador do NIGEP - \\ Núcleo de Estudos Integrados em Geomorfologia, Geodiversidade e Patrimônio, Universidade Regional do Cariri - \\ URCA. E-mail: marcelo.mourafe@urca.br \\ (b) Graduando em Geografia. Bolsista de Iniciação Científica - PIBIC-URCA. Pesquisador do NIGEP - Núcleo de \\ Estudos Integrados em Geomorfologia, Geodiversidade e Patrimônio, Departamento de Geociências, Universidade \\ Regional do Cariri - URCA. Email: joaovictorvk20@gmail.com \\ (c) Graduanda em Geografia. Departamento de Geociências, Bolsista do GeoPark Araripe,Universidade Regional do \\ Cariri - URCA, Email: josiellyurca@gmail.com
}

\section{Eixo: GEODIVERSIDADE, GEOARQUEOLOGIA E PATRIMÔNIO NATURAL}

\begin{abstract}
Resumo
A ciência geográfica se notabiliza pelo estudo da complexa e histórica relação entre natureza e sociedade, utilizando, direta e indiretamente, conceitos-chave, tais como: espaço, região, território, lugar, escala e paisagem. Estes conceitos foram fundamentais também para a diversificação de ramos da Geografia, como a Geografia Cultural que, apoiada no conceito de paisagem, aprofundou a relação de influência do meio natural sobre as manifestações culturais. Apoiados neste ramo e neste conceitochave, apresentamos uma proposta de estudo que perfaça a análise da influência da geodiversidade sobre a cultura, tal qual pode ser verificado, por exemplo, no GeoPark Araripe, mas que não apresenta-se suficientemente cientificizado. Desta forma, o objetivo deste trabalho é apresentar uma proposta inicial para a Geocultura, um ramo geográfico que estude a relação entre a geodiversidade (e seus segmentos - geoconservação, geoturismo e geoeducação), sua influência sobre as manifestações culturais (materiais ou imateriais) e suas possíveis aplicabilidades e implicações correlatas.
\end{abstract}

Palavras chave: Patrimônio, Geoconservação, Geoturismo, GeoPark Araripe, Geossítios

\section{Introdução}

No livro "Sapiens - uma breve história da humanidade" (HARARI, 2016), Yuval Harari descreve a história humana e a importância das mutações genéticas e das pressões ambientais no desenvolvimento dos humanos arcaicos, iniciada há 2 milhões de anos com o surgimento de uma nova espécie humana, o Homo erectus, notabilizada pelo desenvolvimento de uma nova tecnologia de ferramentas de pedra, mas que continuou a mesma por toda a sua existência.

Por sua vez, desdeo período que Harari classifica como a "Revolução Cognitiva" (há cerca de 70 mil anos), o Homo sapiens tem sido capaz de mudar seu comportamento rapidamente, transmitindo novos comportamentos a gerações futuras sem a necessidade de qualquer mudança genetica ou ambiental, 
transformando suas estruturas sociais, relações interpessoais e atividades econômicas em intervalos cada vez menores. Isso foi essencial para colocar esta espécie no topo da cadeia alimentar do planeta Terra (HARARI, 2016).

Ou seja, o conjunto de habilidades e novas capacidades que podemos colocar sob o que entendemos como "cultura", foi fundamental para a evolução humana desde seus primórdios, ao possibilitar, dentre outras coisas, a capacidade de transmitir maiores quantidades de informação sobre o mundo à nossa volta, sobre as relações sociais, sobre coisas que não existem concretamente, como espíritos, nações, empresas; possibilitando o planejamento e as realizações de ações complexas (como caçar animais maiores), formar grupos sociais maiores e coesos, permitindo a cooperação de pessoas estranhas entre si e permitindo rápidas inovações do comportamento social (HARARI, 2016).

A cultura, desde tais primórdios, é fundamental para nós, enquanto espécie em evolução, enquanto seres urbanos, rurais, seres modernos, pós-modernos, artistas, trabalhadores, pessoas dos mares, dos desertos, das florestas, das metrópoles ou do sertão, nos canaliza na direção de causas comuns, em torno de valores locais ou universais, nos dota de diferenças e nos afasta também.

Nossa relação com o meio natural sempre existiu, se diferenciando a partir dos instrumentos e das formas com que modificamos e transformamos o espaço, imprimindo marcas e causando impactos na natureza, ao passo que a mesma, dialeticamente, também influenciou as formas de vida dos diversos segmentos humanos, estreitando portas por um lado, abrindo amplas possibilidades por outro, influenciando no surgimento, na consolidação ou no desaparecimento de inúmeras culturas.

A partir deste preâmbulo, o objetivo deste trabalho é apresentar uma proposta inicial para o que denominados como geocultura, um ramo científico com base no arcabouço teórico geográfico, que estude a geodiversidade e seus segmentos: geoconservação, geoturismo e geoeducação, com ênfase na influência que as rochas, os minerais, os fósseis, as formas relevos, as geoformas e os solos tiveram e têm sobre as manifestações culturais humanas, sejam elas materiais ou imateriais, as implicações associadas e suas possíveis aplicabilidades.

\section{Materiais e Métodos}

A natureza da pesquisa fundamentou-se em uma abordagem de cunho qualitativo que, de acordo com Gil (1996), visa a compreensão ou interpretação de processos de forma complexa e contextualizada e se caracteriza como um plano aberto e flexível. Quanto aos fins esta investigação se caracterizou como descritiva. 
No tocante às técnicas de pesquisa, os procedimentos desenvolvidos foram baseados, por um lado, em um criterioso levantamento bibliográfico, com a realização de um estudo sistematizado, investigando materiais publicados em periódicos de revistas científicas estrangeiras e nacionais, em livros clássicos para a literatura científica ou atuais, com levantamento dos principais referenciais teóricos e metodológicos pertinentes ao objetivo proposto aqui, com ênfase no conceito-chave da paisagem, em elementos teóricos da geografia cultural, da geodiversidade e seus segmentos.

\section{Pressupostos teóricos geográficos}

A ciência geográfica se notabiliza pelo estudo da complexa e histórica relação entre natureza e sociedade, utilizando, direta e indiretamente, conceitos-chave, tais como: espaço, região, território, lugar, escala e paisagem. Estes conceitos foram fundamentais também para a diversificação de ramos dentro da Geografia, como a geografia cultural que, apoiada no conceito de paisagem, aprofundou a relação de influência do meio natural sobre as manifestações culturais, dentre outras contribuições.

Apoiados nesse ramo e nesse conceito-chave, apresentamos um embasamento teórico básico que pode apoiar o desenvolvimento da geocultura. Vamos à uma breve discussão sobre eles.

\section{Paisagem}

A noção de paisagem já está presente na memória da humanidade antes mesmo da elaboração do conceito, cuja ideia embrionária já existia baseada na observação do meio. O conceito atrelado a essa concepção, conforme Maximiano (2004), parece ter surgido com Humboldt no século XVIII, que em suas análises partiu da observação da vegetação para caracterizar um espaço e das diferenças paisagísticas da vegetação para aplicar o método ao mesmo tempo explicativo e comparativo.

Desde então, a importância desse conceito na história do pensamento geográfico tem variado ao longo do tempo, tendo sido relegado a uma posição secundária durante os predomínios das escolas da Geografia Clássica, da Nova Geografia e da Geografia Crítica, suplantado pela ênfase nos conceitos de região, espaço, território e lugar (CORRÊA e ROSENDAHL, 1998).

Após 1970 se verificou a retomada do conceito de Paisagem, embasada em novas acepções fundadas em outras matrizes epistemológicas. Esse período viu também o surgimento da Geografia Humanista que foi, na década seguinte, acompanhado da retomada da Geografia Cultural. Assentada na subjetividade, na experiência e no simbolismo, a Geografia Humanista permitiu que a Paisagem se tornasse um conceito revalorizado (CORRÊA e ROSENDAHL, 1998; CORRÊA, 1995). 
Em termos de método, que é o ponto onde precisamos avançar em relação à geocultura, Humboldt propõs o "empirismo raciocinado", isto é, a intuição a partir da observação, onde o geógrafo deveria contemplar a paisagem de uma forma quase estética. Ou seja, a paisagem causaria no observador uma "impressão", que combinada com a observação sistemática dos seus elementos componentes e filtrada pelo raciocínio lógico, levaria à explicação da causalidade das conexões contidas na paisagem observada. Desta contemplação adviria a explicação (MORAES, 1998).

Sob tal perspectiva, a paisagem geográfica (entendida como um conceito de unidade na Geografia) foi elaborada para tratar da associação peculiarmente geográfica dos fatos, isto é, como um conjunto de formas naturais e culturais associadas em uma dada área, sendo analisada morfologicamente através da integração das formas entre si e o caráter orgânico, ou quase orgânico, delas. Segundo essa perspectiva, os fenômenos que compõem uma área não estão simplesmente reunidos, mas estão associados e são interdependentes (MOURA-FÉ, 2014; SAUER, 1998).

Sendo assim, especificamente no tocante à dimensão antrópica, a modificação de uma dada área pela sociedade e sua apropriação para o seu uso são importantes para a ocorrência da sucessão dessas paisagens como uma sucessão de culturas. Sendo assim, a paisagem natural é submetida a uma transformação social, o último e, na visão de Sauer (1998), o fator mais importante.

Esta sucessão de paisagens associada como uma sucessão de culturas, bem como a análise per si de cada uma delas, é uma abordagem fundamental para pensarmos como a natureza, notadamente, a geodiversidade, se relacionou com o desenvolvimento cultural das pessoas, das comunidades, das sociedades. Ou seja, o conceito de paisagem geográfica já apresenta uma base teórica consolidada que pode ser usada para o desenvolvimento da geocultura.

\section{Geografia Cultural}

A relação da sociedade com a natureza, além de proporcionar transformações no espaço e nas paisagens, envolve a cultura, que é assunto quase obrigatório quando se perfaz a interligação entre a história de uma determinada população e seu desenvolvimento em um determinado espaço, por exemplo. A temática da cultura está inserida no debate geográfico, principalmente quando se refere a extração de matéria prima para as construções e transformações no espaço (COSTA e ROCHA, 2010; SANTOS, 1996), embora haja inúmeras formas diferentes de correlação.

Da natureza sempre extraimos aquilo que era essencial pra nossa sobrevivência, o que filosoficamente, Gonçalves (2008) aponta que: 
O homem arrancou os deuses da natureza e passou a destruí-la como se ele próprio fosse divino, cheio de poderes absolutos. A partir de então, a natureza começou a perder o seu status de mãe da vida. O desejo desenfreado pelo poder e pelo dinheiro, fez com que o homem mudasse sua concepção como parte do natural (GONÇALVES, 2008, p. 172).

A extração da matéria prima proporcionou à sociedade construir bens materiais cada vez mais sofisticados, moldando ainda valores imateriais, que são, cada um ao seu modo, dotados de significados, memórias, histórias, vivências e emoções, dando à diferentes grupos sociais, identidades particulares.

Por sua vez, apesar da natureza ser transformada em construções sociais, que para muitos faz parte do que entendemos como parte da cultura de um povo, o meio natural também pode ser considerado como algo de suma importância para a valorização da identidade de uma comunidade, ou seja, patrimônios naturais podem ser perfeitamente entendidos como patrimônios culturais, pesando nesta associação, basicamente, o nível de inter-relacionamento entre natureza, cultura e as pessoas.

Corroborando esta assertiva, Pelegrini (2006) afirma que os patrimônios culturais não se circunscrevem apenas a bens materiais, construídos socialmente, mas também ao meio ambiente e a natureza, fazendo-se assim presentes nas mais diversas formas de manifestações imateriais. E ainda complementa que "a percepção da herança imaterial torna-se fundamental para a integração da população com suas próprias condições de existência, com a natureza e o meio ambiente" (PELEGRINI, 2006, p. 126).

De maneira geral, conforme Eagleton (2011), "cultura" é considerada uma das duas ou três palavras mais complexas de nossa língua, ao passo que sua oposição ao que entendemos como "natureza" parece ser um ponto menos controverso dessa complexidade, embora, etimologicamente falando, seja um conceito derivado do de natureza.

A raiz latina da palavra "cultura" é colere, o que pode significar desde cultivar e habitar a adorar e proteger. Assim, se cultura significa cultivo, um cuidar que é ativo, "daquilo que cresce naturalmente, o termo sugere uma dialética entre o artificial e o natural, entre o que fazemos ao mundo e o que o mundo nos faz" (EAGLETON, 2011, p. 11). Eis na essência da palavra cultura a relação fundamental entre sociedade e natureza.

Inserida nesse contexto, a geografia cultural tem como objetivo "entender a experiência dos homens no meio ambiente e social, compreender a significação que estes impõem ao meio ambiente e o sentido dado às suas vidas. A abordagem cultural integra as representações mentais e as reações subjetivas no campo da pesquisa geográfica" (CLAVAL, 2002, p. 20). 


\section{OS DESAFIOS DA GEOGRAFIA FÍSICA NA FRONTEIRA DO CONHECIMENTO \\ Instituto de Geociências - Unicamp \\ Campinas - SP \\ 28 de Junho à 02 de Julho de 2017}

A geografia cultural se interessa pelas obras humanas que se inscrevem na superfície terrestre e imprimem uma expressão característica. Enquanto geógrafos, estamos acostumados a considerar a gênese das áreas físicas, razão básica sobre a qual podemos estender o mesmo tipo de observações à área cultural. Aliás, a área cultural do geógrafo consiste unicamente nas expressões do aproveitamento humano da superfície (SAUER, 2014).

A partir de diversas derivações epistemológicas associadas a estas conceituações, vale frisar a correlação com o conceito de paisagem, onde, conforme Claval (2002):

A paisagem não se apresenta tão-somente como um reflexo do funcionamento passado ou presente da sociedade. As relações emocionais entre a paisagem e o observador são analisadas. O papel da paisagem nas estratégias de poder e de dominação é explorado. A significação da paisagem na construção ou na preservação das identidades é ressaltada (CLAVAL, 2002, p. 26).

As possibilidades que, por um lado, a geografia cultural apresenta no seu bojo teórico específico, ao permitir e fomentar cientificamente a abordagem cultural da relação entre natureza e sociedade, embora dê mais ênfase nas marcas sociais na natureza, do que na influência da natureza sobre a cultura (foco da geocultura); e por outro lado, do diálogo consolidado com o conceito de paisagem, importante como vimos acima, apontam de forma concreta que a geocultura tem nesses dois âmbitos uma base teórica que pode e deve ser desenvolvida.

\section{Aplicabilidades geoturísticas}

Em que pese a necessidade de seu desenvolvimento teórico, a geocultura apresenta elementos interessantes de estudo no território do GeoPark Araripe, os quais podem, inclusive, subsidiar o desenvolvimento de estudos de caso que irão, provavelmente, corroborar ou refutar o embasamento téorico a ser desenvolvido.

O GeoPark Araripe é um território com limites definidos (Figura 1), que possui notável patrimônio geológico, paleontológico, geomorfológico (geodiversidade), ecológico (biodiversidade), arqueológico e cultural, com amplas possibilidades de aplicação turística. Sua área territorial é de $3.441 \mathrm{~km}^{2}$, abrangendo 06 (seis) municípios: Crato, Juazeiro do Norte, Barbalha, Missão Velha, Nova Olinda e Santana do Cariri, dotados de 9 (nove) geossítios: Batateiras, Colina do Horto, Riacho do Meio, Cachoeira de Missão Velha, Floresta Petrificada, Ponte de Pedra, Pedra Cariri, Pontal de Santa Cruz e Parque dos Pterossauros.

Um geoparque, de maneira geral, se notabiliza como um espaço delimitado geograficamente, cujas principais atrações turísticas são denominadas como geossítios, locais dotados de relevante geodiversidade 


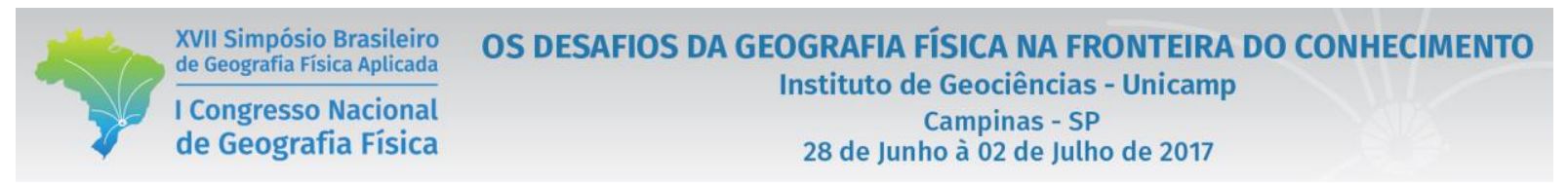

(que engloba a geologia, geomorfologia e pedologia e seus diversos atributos), notabilizando-se como espaços de conservação (geoconservação) e de aplicações turísticas (geoturismo) (MOURA-FÉ, 2015) e educativas, a geoeducação (MOURA-FÉ et al., 2016).

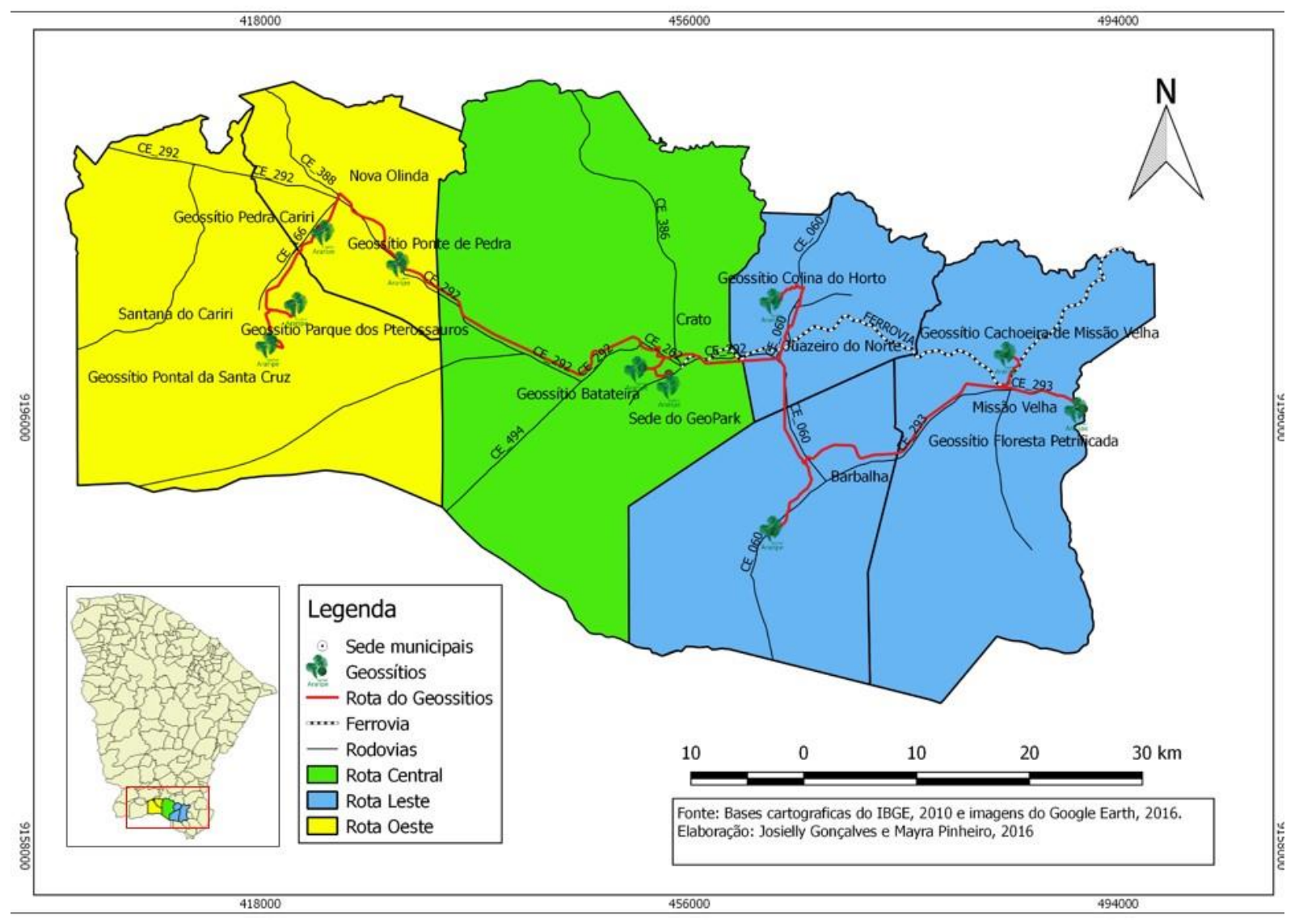

Figura 1 - Mapa do território do GeoPark Araripe, região sul do Estado do Ceará, com indicação dos geossítios abertos para visitação, conforme roteiros turísiticos em desenvolvimento.

A geodiversidade da região do Cariri, notabilizada nos geossítios do GeoPark Araripe, é francamente atrelada à significativos elementos da biodiversidade e da cultura, sob diferentes expressões materiais e imateriais, proporcionando inúmeras formas de realizar o geoturismo e atividades de geoeducação, fundamentais para promover o conhecimento e, por conseguinte, uma maior identificação e formas mais concretas de proteção e geoconservação (MOURA-FÉ, 2016).

Apesar da sua relevância, muitas pessoas que moram ou que visitam a região do Cariri cearense não conhecem as marcas culturais associadas à geodiversidade, presentes diretamente e indiretamente nas mais diversas formas de artesanato (com madeira, com calcário, com barro cru ou cozido, com palha), nos 
mitos sobre castelos e princesas associadas às rochas, relevos, rios e nascentes, lendas contadas por meio da história oral há várias gerações, na relação histórica com o rico patrimônio fossilífero, com as águas das nascentes que formam o chamado "vale do Cariri", com a relação de identidade regional com o grande modelado da chapada do Araripe, nas letras das canções, nas rimas dos córdeis, nas danças, nas ferramentas, nas roupas, nos calçados, nas casas, nas palavras e nos gestos das pessoas.

Como se sabe, o turismo em seu segmento sustentável, não se restringe apenas a observações de paisagens ou obras arquitetônicas. Pelo contrário, diversos destinos turísticos têm ganhado espaço e notoriedade ao dar uma espécie de "passo adiante", apresentando a correlação entre natureza e cultura de uma determinada região, e o Cariri é (mais uma vez) privilegiado neste quesito.

Por sua vez, a elaboração, adoção e divulgação dessas informações entre geodiversidade e cultura no geoturismo, um dos ramos do turismo sustentável (junto com o ecoturismo, o turismo de aventura, o turismo rural, dentre outros), pode trazer, para além da notoriedade da cultura das comunidades que vivem no Cariri, melhorias na qualidade de vida das mesmas, ao passo que o geoturismo inclui, necessariamente, a participação da comunidade em suas atividades (MOURA-FÉ, 2015).

A aplicabilidade turística das informações que deverão surgir com o desenvolvimento da geocultura poderão se dar sob as mais diversas formas, sendo agregadas, por exemplo, às placas, aos textos que apresentam o escopo de apresentação dos geossítios, às maquetes, aos mapas, às falas dos guias e condutores turísticos, agregando valor e ampliando a capacidade de atração turística dos geossítios.

Cabe lembrar que essa forma de turismo, além de proporcionar meios para o desenvolvimento sócioeconômico local, tem em si, também, o intuito de garantir a conservação dessas áreas naturais, conhecidas e reconhecidas por serem dotadas de relevantes patrimônios natural e cultural. Estes, aliás, são os valores fundamentais dos geoparques da UNESCO (Organização das Nações Unidas para a Educação, Ciência e Cultura), incluindo o GeoPark Araripe, a saber:

I. Promover a conservação do patrimônio natural (geodiversidade e biodiversidade) e do patrimônio cultural associado - (geo)cultura;

II. Desenvolvimento socioeconômico sustentável das comunidades locais, a priori, aquelas situadas próximas aos geossítios, através da geoeducação e do geoturismo, objetivando a identificação, aproximação e co-gestão desses espaços (conhecer/cuidar/gerir).

Em suma, o geoturismo apresenta-se como uma importante alternativa de conhecimento e valorização da geocultura, dessa relação tão instigante entre a geodiversidade e a cultura, tão característicos do Cariri 
cearense, campo de estudo que utilizaremos para o desenvolvimento deste conceito, e, ao mesmo tempo, como uma forma de desenvolvimento sócioeconômico das comunidades detentoras dessa geocultura.

\section{Considerações Finais}

Apresentamos aqui, conforme frisado no objetivo apresentado, uma proposta inicial da geocultura, um ramo científico com base no arcabouço teórico geográfico (no conceito de paisagem e na geografia cultural), que deve fazer a análise da geodiversidade e seus segmentos: geoconservação, geoturismo e geoeducação, com ênfase na influência que as rochas, os minerais, os fósseis, as formas relevos, as geoformas e os solos tiveram e têm sobre as manifestações culturais, sejam elas materiais ou imateriais, as implicações associadas e suas possíveis aplicabilidades.

Vale frisar que, diferentemente da geografia cultural, que apresenta no seu bojo teórico específico uma abordagem cultural da relação entre natureza e sociedade, dando mais ênfase nas marcas sociais na natureza; a geocultura busca analisar a influência da natureza sobre a cultura - material e imaterial.

Em termo de prognóstico, dois ramos se desdobram e se apresentam no horizonte: (1) o desenvolvimento teórico do conceito de geocultura, pari passo (ou não), com (2) o desenvolvimento de métodos e técnicas que proporcionem a sua aplicabilidade, o que pode ser facilitado no contexto territorial do GeoPark Araripe e todo o rico campo de estudo do Cariri cearense.

Essa base teórica da geocultura deve, dentre outras possibilidades, embasar a elaboração de um conjunto de ações e estratégias de aplicação no geoturismo, possivelmente em outros ramos do turismo sustentável também, devendo alcançar ainda a geoeducação, outro conceito com aplicabilidades metodológicas em desenvolvimento. Para isso, a contribuição de outros pesquisadores, outros grupos de pesquisa, além do próprio desenvolvimento dos estudos sobre geoeducação, os quais estão sendo estruturados em um projeto de pesquisa, são fundamentais.

\section{Agradecimentos}

Os resultados deste trabalho fazem parte do projeto de pesquisa intitulado: "Geocultura: contribuição teórica e desenvolvimento da aplicabilidade no GeoPark Araripe", desenvolvido pelos autores deste artigo, o qual é financiado pelo Programa Institucional de Bolsas de Iniciação Científica da Universidade Regional do Cariri (PIBIC-URCA), a quem agradecemos pelo apoio concedido através da concessão da bolsa de iniciação científica. 
Os autores também agradecem à geógrafa Mayra Pinheiro pela contribuição na elaboração do mapa apresentado na figura 1 .

\section{REFERÊNCIAS}

CLAVAL, P. “A volta do Cultural” na Geografia. Mercator (Fortaleza-CE), v. 01, n. 01, p. 19-28. 2002.

CÔRREA, R. L. Espaço, um conceito-chave da Geografia. In: CASTRO, I. E. et al. (org.). Geografia: conceitos e temas. Rio de Janeiro: Bertrand Brasil, 1995.

CÔRREA, R. L. e ROSENDAHL, Z. (org.). Paisagem, tempo e cultura. Rio de Janeiro: EdUERJ, 1998.

COSTA, F. R. e ROCHA, M. M.. Geografia: conceitos e paradigmas - apontamentos preliminares. Revista GEOMAE, Campo Mourão, PR, v. 1 n 2, p. 25-56, 2010.

EAGLETON, T. A ideia de cultura. Trad. Sandra Castello Branco. 2 ed. São Paulo: Editora Unesp, 2011. 208 p.

GIL, A. C. Como elaborar projetos de pesquisa. 3 ed. São Paulo: Atlas, 157 p. 1996.

GONÇALVES, J. C. Homem-natureza: uma relação conflitante ao longo da história. São Paulo, Revista Multidisciplinar da UNIESP, n 06, 2008.

HARARI, Y. N. Sapiens - Uma breve história da humanidade. Trad. Janaína Marcoantonio. 18 ed. Porto Alegre: L\&PM, 2016. 464 p.

MAXIMIANO, L. A. Considerações sobre o Conceito de Paisagem. Revista RA`E GA, n. 8, p. 83-91, 2004.

MORAES, A. C. R. Geografia. Pequena história crítica. 14 ed. São Paulo: Hucitec, 1998.

MOURA-FÉ, M. M. GeoPark Araripe e a geodiversidade do sul do Estado do Ceará, Brasil. Revista de Geociências do Nordeste., v. 2, n. 1, p.28-37, 2016.

Geoturismo: uma proposta de turismo sustentável e conservacionista para a Região Nordeste do Brasil. Sociedade \& Natureza, v. 27, n. 1, p. 53-66, Uberlândia-MG: 2015.

A Análise Ambiental Integrada e sua Construção Teórica na Geografia Física. Revista OKARA: Geografia em debate (João Pessoa-PB), v.8, n.2, p. 294-307, 2014.

MOURA-FÉ, M. M.; PINHEIRO, M. V. A.; JACÓ, D. M.; OLIVEIRA, B. A. Geoeducação: a educação ambiental aplicada na geoconservação. In: Educação Ambiental \& Biogeografia. 1 ed. Ituiutaba-SP: Barlavento, 2016, v. II, p. 829-842.

PELEGRINI, S. C. A. Cultura e Natureza: Os desafios das práticas preservacionistas na esfera do Património cultural e ambiental. Revista Brasileira de História, São Paulo, Universidade Estadual de Maringá, v. 26, n 51, p. 115-140, 2016.

SANTOS, J. L. O que é cultura. 16 Ed. São Paulo: Editora Brasiliense, 1996.

SAUER, C. O. Geografia Cultural. In: CORREAA, R. L. e ROSENDAHL, Z. (Org.). Introdução à Geografia Cultura. 6 ed. Rio de Janeiro: Bertrand Brasil, 2014. 224 p.

. A Morfologia da Paisagem. In: CORRÊA, R. L. e ROSENDAHL, Z. (org.) Paisagem, tempo e cultura. Rio de Janeiro: Ed UERJ, 1998. 